\title{
Selection of stock funds using information that is not observable or measurable
}

\author{
Rodrigo Coccarelli Marroco do Amaral' \\ (D) https://orcid.org/0000-0003-4137-9371 \\ Email: rodrigomarroco@hotmail.com
}

\author{
Ricardo Pereira Câmara Leal1 \\ (D) https://orcid.org/0000-0002-4516-9788 \\ Email: ricardoleal@coppead.ufrj.br
} ${ }^{1}$ Universidade Federal do Rio de Janeiro, Instituto COPPEAD de Administração, Departamento de Finanças e Controle Gerencial, Rio de Janeiro,
RJ, Brazil

Recieved on 09.25.2019 - Desk acceptance on 10.07.2019 - $3^{\text {rd }}$ version approved on 03.26.2020

Editor-in-Chief: Fábio Frezatti

Associate Editor: Fernanda Finotti Cordeiro

\begin{abstract}
The aim of this paper is to investigate whether the flows and the future returns of stock funds are related to investors' unobservable information. This article extends the knowledge about investment decisions regarding stock funds and considers a representation of unobservable information that until now has not been contemplated by the Brazilian literature. Understanding decisions to invest in stocks has become more important since the fall in interest rates and migration toward equity investments. The use of unobservable information for making investment decisions is important when choosing stock funds and the return gap could be added to the list of information offered to investors. The return gap measures the value added by managers in relation to the most recently disclosed complete lagged portfolio and was calculated every month for every asset in the portfolios of every fund in the sample disclosed with a three-month lag. A parsimonious sample was used of 22 actively managed funds in the period from January of 2010 to December of 2018, containing one from every one of the 22 biggest independent Brazilian managers, because it is laborious to calculate this metric. The return gap represents unobservable information about a fund. Investors that direct their capital toward stock funds with a higher historical return gap tend to obtain higher returns in out-of-sample tests, suggesting persistence of the returns of these funds and supporting the importance of unobservable information. Investors that directed their capital toward funds with lower historical return gaps could also obtain positive alphas in some cases, indicating that some managers were neglected. The fund flow results were inconclusive.
\end{abstract}

Keywords: return gap, fund flow, fund performance, stock funds, Brazil. 


\section{INTRODUCTION}

All types of investment funds managed USD 50 trillion at the end of the first quarter of 2019 , of which $44 \%$ were invested in stock funds. The Brazilian investment fund industry was the $11^{\text {th }}$ biggest in the world and the biggest in Latin America in amount of assets, according to the Investment Company Institute (ICI, 2019).

Brazilian fund managers were responsible for managing more than BRL 284 billion in assets in December of 2018, according to the Brazilian Association of Financial and Capital Market Entities (Anbima, 2018). However, stock funds accounted for only $7 \%$ of that value, while $43 \%$ were invested in the fixed income category (Anbima, 2018). The long period with high interest rates in Brazil may be in a transition phase, as the main reference rates of the economy have recently reached historically low values, while the Bovespa index (Ibovespa) has been successively presenting maximum highs, according to data extracted from the Economatica ${ }^{\circledR}$ database. This market movement encourages migration from more conservative investments toward riskier alternatives, such as stock funds (Daltro \& Leal, 2019).

Choosing an stock fund is therefore an increasingly important investment decision and motivated this article (Mendonça et al., 2017; Oliveira \& Souza, 2015). There is a large quantity of stock funds and managers and the decisionmaking process can involve several variables. Among these are the fund's historical performance, the management and incentive fees charged by the managers, the phase of the stock market, the risk-adjusted indicators, as well as qualitative and subjective aspects, such as the manager's and their institution's ability and reputation (Mendonça et al., 2017; Oliveira \& Souza, 2015; Silva et al., 2018).

Investors may have information about a fund's future performance that is not contemplated in the parameters that are directly observable by means of public or historical data, as their decision-making process may occur in a more complex way than through merely analyzing these observable parameters, and it may contemplate qualitative and subjective aspects (Dyakov \& Verbeek, 2019). The return gap of Kacperczyk et al. (2008) captures the impact of fund mangers' actions and decisions that are not observable by means of historical data and other public information. These authors affirm that the return gap has strong predictive power regarding the future performance of stock funds in the United States.

In the case of the Brazilian stock market, Instruction 555 of the Comissão de Valores Mobiliários (CVM, 2014), the Brazilian capital market regulator, says that a fund manager should disclose their portfolio composition monthly, within up to 90 days after the close of the month, or exceptionally within 180 days; in the latter case, via CVM authorization, to reveal the identification of positions whose disclosure may be detrimental to operations underway. Thus, a fund's return gap in a particular month in Brazil will be the return actually obtained by the stock fund in the three months following full portfolio disclosure without exceptions, minus the disclosed portfolio's buyand-hold return in the previous three months, during the same three-month period, net of the management fee.

This article aims to verify whether there is a positive relationship between more favorable unobservable information, represented by the return gap, and the net capital allocation flow (inflows and outflows of stock funds). The second objective is to determine whether the future return of stock funds maintains a positive out-of-sample relationship with the return gap, even after controlling for the risk factors from Carhart's (1997) model, suggesting that the investors that operate in the Brazilian market are capable of identifying good managers by means of parameters that are not directly observable.

This article makes new contributions by using unobservable information, represented by the return gap, to study the choice of stock funds in the Brazilian market, although similar analyses have been made for the U.S. market. It also therefore contributes by extending the literature on investors' decision-making process regarding managers and stock funds, with the employment of the metric that represents information that previous Brazilian studies have not been able to consider as they have been limited to funds' public and objective characteristics and their historical data (Mendonça et al., 2017; Oliveira \& Souza, 2015; Sanvicente, 2002; Silva et al., 2018).

The sample analyzed here considered 22 stock funds managed by the biggest stock fund managers in the country, from January of 2010 to December of 2018, chosen in order of assets under management and filtered according to other criteria in order to obtain a representative sample of the Brazilian stock fund market and also considering the need for parsimony due to the laborious task of monthly estimating the return of every asset present in every portfolio of every fund.

The results indicate that investors in stock funds would be capable of differentiating managers that will probably have satisfactory performance in the future using information that is not directly observable, represented by the return gap. There was no correlation between the variation in 
the funds' capital allocation flow and their lagged return gaps, even with the inclusion of known determinants of this variable. The sample with the $20 \%$ biggest return gaps presented a significant and positive coefficient in relation to the corresponding future performance, out of sample, indicating persistence in the performance of the managers with better unobservable information. On the other hand, the observations of the quintiles with the smallest return gaps did not present a significant coefficient in relation to future performance, but significant alphas, on average, even in the presence of Carhart's (1997) risk factors, which suggests that some of these managers, although they raised less, may have been underestimated by investors.

Additional tests revealed similar results for the Jensen's alpha. These results are partly consistent with those of Dyakov and Verbeek (2019) and Kacperczyk et al. (2008) for the United States and expand the conclusions of Brazilian articles that have only considered the information available in the databases to select stock funds, by indicating, as would be expected, that investors consider a broader set of information for their decisions (Matos et al., 2015; Mendonça et al., 2017; Oliveira \& Souza, 2015; Silva et al., 2018). The rest of the article is composed of the review of the literature on which the study is based, followed by the methodology section, which describes how the managers and stock funds that compose the sample were chosen, as well as detailing the variables employed. The subsequent section details the results obtained and is followed by the conclusions, limitations, and suggestions for future studies.

\section{LITERATURE REVIEW}

\subsection{Return Gap and Capital Allocation Flow}

The return gap of Kacperczyk et al. (2008) is a measure of value added by the actions of managers benefiting investors in relation to the return that would be obtained if no change was made to the composition of the last portfolio disclosed. These authors used data on more than 2,500 stock funds from the United States in the period from 1982 to 2003 , of which $97.47 \%$ were actively managed. Their main conclusions indicate that the return gap presents significant persistence in the long run both for high and for low performance funds. In addition, the study concludes that the return gap has significant predictive power regarding the future performance of stock funds, as well as identifying funds whose unobservable activities are negatively affecting the fund's return. This study also concluded that the return gap is not affected by the risk adjustments proposed by Carhart (1997), Fama and French (1993), or Jensen (1968).

The literature offers some studies that indicate potential motivators for changes in capital allocation flows, such as the fund's historical performance (Gruber, 1996; Ippolito, 1992; Sirri \& Tufano, 1998) and size (Siri \& Tufano, 1998). Dyakov and Verbeek (2019) extended the work of Ippolito (1992) and Kacperczyk et al. (2008) by studying the relationship between the dynamic of the capital allocation flow in actively managed stock funds in the United States and their return gap. A stock fund's capital allocation flow is the result of its inflows and outflows. These authors employed a panel of approximately 2,500 domestic actively managed stock funds from the United States in the period from 1990 to 2010 and they found a significant and positive relationship between capital allocation and the return gap, which suggests that investors may be able to distinguish between funds that will probably perform well or poorly by using information about the managers reflected in the return gap.

Kwak (2018) also argues that funds with a high return gap and low capital allocation flow are undervalued, while those with a low return gap and high capital allocation flow are overvalued. Kwak (2018) ordered the funds both in terms of return gap and capital allocation flow, and concluded that the future performance of the stock funds with a low return gap and high capital flow significantly tends to be negative, adjusted by Carhart's (1997) risk model. The reciprocal of this conclusion was also confirmed.

\subsection{Determinants of Brazilian Stock Fund Performance}

The literature focused on the Brazilian market indicates that the capital allocation flow in stock funds increases when there is a positive variation in the Ibovespa (Sanvicente, 2002). This author argues that such investor behavior would be coherent with agency theory because it rewards managers with good historical performance and punishes those with inferior performance, but, on the other hand, it is irrational, as past performance should not be an indicator of future performance. However, the author did not confirm the hypothesis that stock funds' flows behavior helps to predict their performance. Januzzi 
et al. (2017) also indicate the inexistence of a statistically significant relationship between the capital allocation flow into stock funds and their return. These authors employed a sample with 497 stock funds classified by Anbima as Active Ibovespa Stocks in the period from December of 2007 to December of 2014.

Stock funds' past returns may have a relationship with their future returns. Andaku and Pinto (2003) used a sample of 84 stock funds in the period from July of 1994 to June of 2001, with the aim of verifying the existence of a direct relationship between their past and future performances. The authors did not confirm performance persistence in the investments with terms shorter than one year, corroborating the argument that historical performance in the Brazilian market is not a good indicator of future performance, at least in the short term. Nerasti and Lucinda (2016) extended the analysis of Andaku and Pinto (2003) and reached similar conclusions regarding persistence, by applying four risk adjustment models to a sample of 1,714 stock funds in the period from 2001 to 2014.

Besides past returns, other variables may be determinants of stock fund performance. Ceretta and Costa (2001) already argued that Brazilian investors employ other factors besides risk-return weighting during their decision-making process. These authors contemplated "desirable" attributes (related to return) and "undesirable" ones (related to risk) possibly considered by investors in the capital allocation process. Milani and Ceretta (2012) used 139 active and passive management stock funds in the period from 2001 to 2009 to determine the impact of the size of the fund's net assets under management (AUM) and its longevity on its performance and they found a positive relationship for the fund's AUM and a negative one for its longevity. Oliveira and Souza (2015) evaluated 173 stock funds during the period from 2003 to 2010 to study the probability of an stock fund that has presented good performance in relation to the rest being able to maintain that performance in the following period. The model developed was right in $81 \%$ of the cases and identified the management and incentive fees, the Treynor ratio, the generalized Sharpe ratio, and the Modigliani ratio as variables that should be considered by the investor when choosing funds. Matos et al. (2015) studied 68 stock funds in the period from January of 1998 to June of 2007 and affirmed that winning stock funds tend to be newer, managed by non state owned financial institutions, and they charge lower management fees than those charged by losing funds, and a incentive fee.

Mendonça et al. (2017) proposed a scoring model based on two incentive measures and eight directly observable characteristics to help investors in choosing Brazilian actively managed funds with a positive and significant Jensen's alpha. Performance was considered in terms of return and Sharpe ratio and the following stand out among the characteristics mentioned: nature of the manager (independent or not), type of investor the fund focusses on (qualified or not), size and longevity of the fund, use of leverage, constitution of a fund investing in shares of other funds (funds of funds), and charging an incentive fee. Based on a sample of 1,417 stock funds analyzed in the period from 2004 to 2014 , the authors conclude that the stock funds with the highest score frequently tend to obtain significantly positive alphas and they are rarely negative.

In summary, there are several variables obtained from directly observable parameters and historical datasets associated with fund performance to try to identify what would be relevant in the investor's decision-making process, the main ones being: longevity; AUM; charging incentive fees; historical performance, risk-adjusted or not; and manager independence. However, Dyakov and Verbeek (2019) and Kacperczyk et al. (2008) state that these parameters would not be sufficient to completely understand the investor's decision-making process. This article thus extends this literature by assessing whether there are other aspects that are not directly observable, represented by the return gap, that can contribute to better stock fund selection decisions.

\section{METHODOLOGY}

\subsection{Management Company Selection}

The managers were classified according to their size, according to the assets under management in stock funds disclosed in December of 2018, in accordance with the AUM ordering for the "Stocks" (“Ações") class disclosed by the Anbima (2018) publication. The fund's size and its longevity are characteristics previously identified as being important by the Brazilian literature and will be used as control variables in the analysis (Mendonça et al., 2017; Milani \& Ceretta, 2012). 
The stock funds linked to large financial institutions are expected to have a lower return and volatility than the others, as stock fund managers affiliated with financial conglomerates appear to be very concerned about volatility and the possible loss of clients if they manage a very aggressive fund (Matos et al., 2015; Mendonça et al., 2017). The decision was therefore made to consider only independent managers in the sample, which controls for this aspect of the manager's nature and contributes to the parsimony in the number of stock funds considered, as Mendonça et al. (2017) identified manager independence as a possible determinant of Brazilian stock fund performance. Thus, managers associated with large commercial and investment banks operating in Brazil were left out, considering only managers whose main sources of revenue were derived from asset management and whose fund could be accessed by any private individual investor.

After applying these filters, 32 independent managers were chosen who presented the highest AUMs invested in stocks, whose value, in December of 2018, varied from BRL 28 billion (Opportunity) to more than BRL 5 billion, for the second biggest (SPX), to BRL 1 billion, with the vast majority being between BRL 1 and 3 billion (Anbima, 2018). Thus, with the exception of Opportunity, the equity in stock funds of the independent managers was between BRL 1 and 5 billion. This number refers to the AUM the manager invests in stocks and not to their total AUM or to one fund in particular. More details on the selection and exclusion of the managers chosen to compose the sample are available from the authors.

\subsection{Stock Fund Selection}

We chose to select one stock fund from every one of the independent managers chosen for the sample composition so that this was representative of the universe of actively managed Brazilian stock funds, respecting the need for parsimony in relation to the number of stock funds analyzed, because building the database using the monthly calculation of the returns of each asset in the portfolio of a stock fund is laborious and time-consuming.

The sampling period considered used data from January of 2010 (whose information needed to calculate the return gap came from October of 2009) until December of 2018, totaling a nine-year time series. To define the start of the time series, we aimed to maximize the period analyzed while at the same time not including years in which few of the chosen stock funds had been created. For example, in 2009, less than half of the total stock funds analyzed had been created, and so the study considers data as of 2010. The time series ended in the month in which the most recent data were available during the data collection period. During the whole sampling period, the stock funds' portfolio composition data were disclosed monthly by the CVM, with a three-month lag. The Economática ${ }^{\circledR}$ database was employed to obtain the data.

The following were excluded from the sample: pension funds; passive and index funds; long-short funds; funds investing abroad; funds with a history of less than six full years, that is, those created after December of 2012; funds that were mostly invested in other funds; and those that individual investors did not have access to, not even via feeder funds. The stock funds chosen could be temporarily closed for investment at the time the sample was chosen and the investment could also be carried out exclusively via feeder funds. The aim was to exclude exclusive funds or those meant for a restricted number of shareholders. After applying these filters, 22 of the 32 independent managers chosen managed at least one stock fund that met all these pre-requisites.

Next, the analysis was carried out so that the sample was composed of 22 actively managed funds, one for each independent manager chosen. This selection process was carried out via the qualitative observation of characteristics of the stock funds of a manager in December of 2018. The preference criteria for this selection were applied, observing factors such as the fund's AUM and longevity of the data record in the sampling period, seeking to give preference to the biggest and oldest stock fund of a manager, so that there were longer time series of returns. The number of assets in the portfolio and the percentage of the fund's AUM invested in stocks and in national assets were also considered, so that some additional factors identified in the national literature as determinants for stock fund selection were considered in the sample selection (Matos et al., 2015; Mendonça et al., 2017; Milani \& Ceretta, 2012).

This selection process may give rise to some survivorship bias, by not considering the stock funds that no longer exist. Moreover, a random sample of surviving stock funds could be considered. However, a parsimonious sample was preferred that was at the same time representative of the biggest independent managers, that is, those that would receive more investors, instead of funds of small managers that could dominate a random sample, but that would be targeted by few investors. There was, therefore, concern about the economic relevance among the funds of the independent managers chosen. The possible impact of the survivorship bias in this study would be to indicate a positive relationship between the unobservable information and the variables of interest fund allocation and future returns - for the stock funds chosen that may not be present in a bigger or random sample. 
Only the Dynamo Cougar stock fund charged an incentive fee during the period analyzed, as most of the 22 stock funds are master funds. Thus, for the analysis that follows, the incentive fee was not considered in the return gap calculation. It is worth remembering that the existence of an incentive fee has been considered one of the possible determining factors for stock fund selection in the Brazilian literature, and that the characteristics of the sample employed here practically eliminate its influence over the results (Matos et al., 2015; Mendonça et al., 2017; Oliveira \& Souza, 2015).

Finally, it was verified whether the AUM reported by every stock fund in every month was equivalent to the sum of the stock fund's assets and liabilities disclosed by the CVM. The funds whose disclosed AUM frequently diverged from the sum of the assets and liabilities at the CVM were substituted by another from the same manager. The months in which they diverged were only ignored when the funds presented few divergences. More details about the number of observations considered in each period can be observed in Table 1, which shows that all the stock funds participate in the sample as of 2013 . Fourteen of the 22 funds in the sample already existed in the first year of the sample (2010), the mean number of assets in the portfolios varies between 44 and 54, and the number of funds-month removed from the sample due to AUM divergences did not represent more than $14.8 \%$ of the total funds-month of a year, in 2018.

Table 1

Characteristics of the sample

\begin{tabular}{|c|c|c|c|c|c|}
\hline Year & Funds & Assets & Obs. & Divergences & Valid \\
\hline 2010 & 14 & 48 & 130 & 18 & 112 \\
\hline 2011 & 14 & 54 & 168 & 9 & 159 \\
\hline 2012 & 20 & 46 & 208 & 15 & 193 \\
\hline 2013 & 22 & 44 & 263 & 34 & 229 \\
\hline 2014 & 22 & 49 & 264 & 7 & 257 \\
\hline 2015 & 22 & 48 & 264 & 7 & 257 \\
\hline 2016 & 22 & 52 & 264 & 6 & 258 \\
\hline 2017 & 22 & 51 & 264 & 12 & 252 \\
\hline 2018 & 22 & 48 & 264 & 39 & 225 \\
\hline
\end{tabular}

Note: "Funds" is the number of stock funds present in the sample in each year; "assets" is the mean number of assets (stocks, debt securities, etc.) present in the portfolios of the funds analyzed during each year; "obs." is the total number of funds-month in each year, that is, the number of funds analyzed multiplied by the number of months of the year with data for the fund flow and return gap; "divergences" is the quantity of funds-month excluded from the sample because the assets under management (AUM) reported by the fund did not correspond to the sum of assets and liabilities disclosed by the CVM (Brazilian capital market regulator); and "valid" is the difference between the two columns that precede it and correspond to the final total number of observations in each year of the sample.

Source: Elaborated by the authors based on a sample of funds obtained from the Economatica ${ }^{\circledR}$ database.

\subsection{Capital Allocation Flow and Return Gap Calculations}

The stock fund's flow was calculated in the same way used by Dyakov and Verbeek (2019) and Kacperczyk et al. (2008). Equation 1 shows that the percentage variation in the capital allocation flow for fund $i$ in quarter $t\left(\right.$ Flow $\left._{i, t}\right)$ is the difference between the stock fund's AUM at the end of the quarter and the AUM at the start of the quarter adjusted by the fund's return $\left(R_{i, t}\right)$.

$$
\operatorname{Flow}_{i, t}=\frac{A U M_{i, t}-A U M_{i, t-1}\left(1+R_{i, t}\right)}{A U M_{i, t-1}}
$$

The first step will be to calculate the return gap for a sample of Brazilian stock funds. Equation 2 shows the form of the calculation of the return gap of stock fund $i$ in quarter $t\left(R G a p_{i, t}\right)$. Kacperczyk et al. (2008) define the return gap as the difference between the return of fund $i$ in quarter $t\left(R_{i, t}\right)$ and the return of its most recently disclosed portfolio kept unchanged during the quarter, following the buy-and-hold $\left(\right.$ RHold $\left._{i, t}\right)$ strategy, subtracting the quarterly equivalent of the stock fund's management fee (ManFee $\left.{ }_{i, t}\right)$.

The return gap calculation in this article should be obligatorily carried out by considering the returns from the previous three months because the composition of the funds' portfolios is informed monthly by the CVM 
to the market with a three-month lag. Moreover, to avoid quarterly overlaps, only the quarters beginning in January, April, July, and October were considered for the main results, but the tests were replicated for the quarters beginning in the other months. The returns from quarters starting in the other months were not considered simultaneously with the base-case so that the quarterly returns and return gaps did not overlap, generating a strong correlation if a monthly time series of quarterly returns in moving windows was employed.

$$
\operatorname{RGap}_{i, t}=R_{i, t}-\left(\text { RHold }_{i, t}-\text { ManFee }_{i, t}\right)
$$

All variables were calculated on a quarterly basis to form the data panel in which each line contained the variables for each fund-quarter. For example, in the case of the panel with quarters beginning in January, April, July, and October, there will be a line with Flow ${ }_{i, t}$, in the form of equation 1, calculated with the AUM on the last days of business of June $\left(A U M_{i, t-1}\right)$ and of September $\left(A U M_{t}\right)$ of a year and with $R G a p_{i, t-1}$ calculated with the returns estimated with the share prices of the last days of business of March and of June of the same year for a particular stock fund. Thus, $R G a p_{i, t-1}$ refers to the quarter prior to Flow $_{i, t}$ as the subscript $t$ indicates. The next line of the panel will show Flow $w_{i, t}$ calculated with the AUM on the last days of business of September $\left(A U M_{i, t-1}\right)$ and of December $\left(A U M_{t}\right)$ of a year and with $R G a p_{i, t-1}$ calculated with the returns estimated with the share prices on the last days of business of June and September of the same year for the same stock fund, and so on.

The stock funds analyzed invested, on average, 70\% of their assets in stocks during the sample period and, on average, $99.6 \%$ of the values of the assets disclosed in the portfolios of the funds had a code (ticker) mapped and identified in the Economatica ${ }^{\circledR}$ database, which enables the return on the assets in the portfolios $\left(\right.$ RHold $\left._{i, t}\right)$ to be calculated with precision. The composition of the portfolios, the return on the assets that composed the portfolio, the return disclosed by the funds, and the management fee were obtained and calculated based on the Economatica ${ }^{\circledR}$ database.

Some premises were employed in the case of assets without a ticker. The CDI Interbank Certificates of Deposit rate was employed as the return in the following categories: "securities not revealed," "securities unknown," "other investments," "other marketable securities," "government bond repurchase agreements," and "government bonds." The values were maintained and the return was null in the following categories: "accounts receivable," "accounts payable," "available cash," "loans granted and received," "underwriting rights," "swap spread payable," and "swap spread receivable." This was also the case for low liquidity assets that were not traded during the quarter. The return was the variation in the U.S. dollar in relation to the real (BRL) in the period for investments abroad without a code. The return was the variation in the Anbima IDA Geral corporate bonds index in the case of corporate bonds without a registered ticker.

The national literature indicates that the management fee is a relevant factor in choosing stock funds and was considered in both returns present in equation 2 , as the return disclosed by the stock funds $\left(R_{i, t}\right)$ is net of management and incentive fees, and the buy-and-hold return of the portfolio ( $H o l d_{i, t}$ ) was subtracted from the quarterly equivalent of the management fee (Matos et al., 2015; Mendonça et al., 2017; Oliveira \& Souza, 2015). The management fee is disclosed in the form of an annual percentage (for example: $2 \%$ p.a.) and was converted to quarterly by dividing it by four (for example: $0.5 \%$ p.q.). The funds analyzed did not present variations in the management fees during the sample period. The casual observation of the authors indicates that there was a reduction in management fees in low risk (fixed income) or pension funds geared toward investors in general, but this did not occur with the stock funds in the sample.

Jensen's (1968) alpha was employed as a measure of market risk-adjusted return and an alternative to the return disclosed by the stock fund. The alpha was expressed on a quarterly basis and calculated using a function from the Economatica ${ }^{\circledR}$ database that considers, as parameters, the monthly data with a 36-month history of the "Treasury Financial Bill" (Letra Financeira do Tesouro - LFT), maturing in 252 days, and the IBrX 100 index return. Finally, the quarterly return of the Ibovespa was also considered, identified by Sanvicente (2002) as being important for explaining the capital allocation flow on the part of investors.

Other variables identified in the national literature as determinants for choosing stock funds, such as the fund's AUM, its longevity, independence, and management and incentive fees, were considered in the manager and fund selection process and in the return gap calculation, as demonstrated in the previous sections, and the fund's AUM and its longevity were included in the models. The other variables to be employed largely followed the methodology of Dyakov and Verbeek (2019) and are merely variants of the fund return and return gap presented in this article, and are explained in the Results section.

\subsection{Regression Models and Hypotheses}

The first goal of this article is to assess the relationship between fund flow and the return gap. Equation 3 illustrates the form of the models estimated with lagged variables 
in relation to the dependent variable Flow $_{i, t}$, defined in equation 1 , to study its sensitivity in relation to the return gap, defined in equation 2 . The vector $\mathrm{X}_{\mathrm{i}, \mathrm{t}-\mathrm{1}}$ includes, depending on the model, the following variables in period $t-1$, a quarterly period that ends exactly when that of the dependent variable begins: return of the buy-andhold portfolio $\left(\right.$ RHold $\left._{i, t-1}\right)$, a quarterly equivalent at simple interest of the annual management fee $\left(\mathrm{ManFe}_{i, t-1}\right)$, return gap $\left(R G a p_{i, t-1}\right)$, the fund's return $\left(R_{i, t-1}\right)$, the fund's Jensen's alpha $\left(\right.$ Alpha $\left._{i, t-1}\right)$, return on the Ibovespa $\left(\right.$ RIbov $\left._{t-1}\right)$, return on the $\operatorname{IBrX} 100\left(\right.$ RIbrx $\left._{t-1}\right)$, as an alternative to the Ibovespa, and the natural logarithm of the fund's AUM and of its age in years. All variables were calculated on a quarterly basis to form a panel with up to 1,942 funds-month.

$$
\text { Flow }_{i, t}=\beta^{\prime} X_{i, t-1}+\epsilon_{t-1}
$$

$\mathrm{H}_{1}$ is the hypothesis that relates to the first objective of this investigation.

$\mathrm{H}_{1}$ : the return gap of the previous period does not maintain a positive relationship with the variation in the fund flow of a period, as calculated in equation 1 .

The findings of Dyakov and Verbeek (2019) and Kacperczyk et al. (2008) suggest the rejection of $\mathrm{H}_{1}$ in favor of an alternative hypothesis of a positive relationship between the return gap of the previous period and the variation in fund flow. Similarly, the coefficients of the other measures of return are also expected to be positive, depending on the model, and negative for the management fee control variable, as it reduces the returns presented by the funds, and the fund's AUM and age, as the percentage variation of the fund flow of bigger and older funds should be lower than that for smaller and starting funds (Matos et al., 2015; Mendonça et al., 2017; Oliveira \& Souza, 2015; Sanvicente, 2002).

Equation 4 portrays the model that relates the future annual return of a stock fund with the annual return gap and also considers Carhart's (1997) four risk factors. Following the methodology used by Kacperczyk et al. (2008), a measure was created of the annual return gap equal to the cumulative return under the compound interest regime of the quarterly return gaps of the four most recent previous quarters (one year). The series was listed in ascending order in relation to the annual return gap measure and the sample was divided into five, according to the quintiles of the annual return gap. Similarly, the sample was divided into two, according to the median. Regression models of the annual return gap

over the future annual return of the stock funds adjusted to Carhart's (1997) risk factors were estimated for each one of these samples and also for the complete sample.

An additional three-month lag was introduced between the stock fund's annual return and its return gap because the return gap calculation is only possible with a three-month lag, due to the way the funds' portfolios are disclosed by the CVM. For example, the annual return in September of 2017 was compared with the fund's annual return during 2018 because, in December of 2017, an investor could only calculate the annual return gap of the funds relating to September of 2017 and, by allocating their capital according to this information, he or she would obtain returns during 2018. This is, therefore, an out-of-sample test regarding the relationship between the return gaps and the returns of the stock funds.

$\mathrm{H}_{2}$ is the null hypothesis, which relates to the second objective of this investigation.

$\mathrm{H}_{2}$ : the future return of an stock fund is not related to the return gap of the previous period.

The alternative hypothesis is that there is a positive relationship between these variables and it also derives from the work of Dyakov and Verbeek (2019) and Kacperczyk et al. (2008). The regressions were carried out with the stock fund's annual return in quarter $t=5$ as the dependent variable and the annual return gap in quarter $t=0$ as the explanatory variable for each one of the subsamples, as according to equation 4 .

Carhart's (1997) risk factors were obtained from the Center for Finance Studies of the University of São Paulo (Nefin, 2015). This source estimates monthly values of each factor, which were converted into quarterly and annual bases following the same method used for the annual return gap, as already described.

The presence of the risk factors seeks to attenuate the possibility of any relationship between the return gap and the fund's return being due to the omission of these known risk factors. Moreover, in this article, only Carhart's model is considered, as a smaller number of positive and significant alphas are identified with this model in relation to the models with fewer risk factors, such as the capital asset pricing model (CAPM) and the Fama and French (1993) three factors model, due to the inclusion of the factor relating to momentum (Carhart, 1997).

$$
R_{i, t+5}-R_{F}=\propto_{i}+\beta_{i} \times M R P_{t}+s_{i} \times S M B_{t}+h_{i} \times H M L_{t}+w_{i} \times W M L_{t}+\varepsilon_{i, t}
$$

$M R P_{t}$ is the market risk premium factor, calculated in the database obtained as the difference between the return on the portfolio weighted by value formed of all the chosen stocks, according to the criteria of the data providers and the swap rate of 30-day "DI" interbank deposit rate contracts $\left(R_{F}\right) . S M B_{t}$ is the factor related to the risk premium 
of the companies with the lowest market capitalization (small stocks) in annualized form (Fama \& French, 1993). Originally, it was calculated for every month based on the ordering of all the stocks considered in its calculation by the company's market value in December of the previous year. Based on this ordering, three equally-weighted portfolios are formed, where $S M B_{t}$ is the difference between the returns of the portfolio with the smallest and biggest companies, ignoring the intermediate portfolio. Details of the calculation methodology can be examined in the paper by Nefin (2015) and it is well-known in the Brazilian literature on stock funds (Mendonça et al., 2017). $H M L_{t}$ is the factor for the risk premium of the undervalued companies, also known as value stocks, as defined by Fama and French (1993), and estimated by ordering and forming equally-weighted portfolios by the ratio between the company and the market book value. $W M L_{t}$ represents the premium of the winning companies over the losing ones, in the way it was added by Carhart (1997) to the original Fama and French (1993) model, according to the return calculated in the 11 months prior to the month of calculation. These two factors were estimated in a similar way to $S M B_{t}$.

\section{RESULTS}

\subsection{Fund Flow and Return Gap}

Table 2 presents some descriptive statistics. It is interesting to note that the mean return of stock funds was 3.8\% per quarter and that the mean buy-and-hold return of the stock fund's portfolio lagged by three months was $3.2 \%$, consistent with the mean return gap of $0.8 \%$ per quarter, considering the deduction of the mean quarterly management fee of $0.2 \%$, shown in Table 2 . The mean monthly variation in flow was positive by $4.5 \%$ per quarter and the Ibovespa presented a mean quarterly variation of $1.4 \%$.
The correlation between the explanatory variables $R_{i, t}$ and RHold $_{i, t}$ was 0.94 . The correlations between $R G a p_{i, t}$ and $R_{i, t}$ and $R$ Hold ${ }_{i, t}$ were 0.35 and 0.01 , respectively. The alpha correlations with $R G a p_{i, t}, R_{i, t}$, and RHold $_{i, t}$ were $0.07,0.18$, and 0.17 , respectively. The quarterly return of the Ibovespa was highly correlated with the stock funds' returns, being 0.78 and 0.82 for $R_{i, t}$ and $R$ Hold $_{i, t}$, respectively, but only 0.03 with their return gaps $\left(R G a p_{i, t}\right)$. Variables that present very high correlations will not be simultaneously included in the regression models, in order to avoid multicollinearity problems.

Table 2

Descriptive statistics of selected variables

\begin{tabular}{|c|c|c|c|c|c|c|}
\hline Variable & Obs. & Mean & Median & Minimum & Maximum & SD \\
\hline Alpha & 1,473 & 0.016 & 0.013 & -0.037 & 0.126 & 0.019 \\
\hline Flow & 1,938 & 0.045 & -0.001 & -0.870 & 2.547 & 0.224 \\
\hline $\mathrm{R}$ & 1,942 & 0.038 & 0.033 & -0.269 & 0.806 & 0.091 \\
\hline RGap & 1,942 & 0.008 & 0.006 & -0.305 & 0.357 & 0.031 \\
\hline RHold & 1,942 & 0.032 & 0.027 & -0.274 & 0.718 & 0.085 \\
\hline RIbov & 1,942 & 0.014 & 0.006 & -0.305 & 0.357 & 0.031 \\
\hline$R I B r X$ & 1,942 & 0.021 & 0.018 & -0.148 & 0.302 & 0.093 \\
\hline ManFee & 1,942 & 0.002 & 0.001 & 0.000 & 0.005 & 0.002 \\
\hline LFT & 1,942 & 0.025 & 0.026 & 0.016 & 0.034 & 0.006 \\
\hline $\begin{array}{l}\mathrm{AUM}(\mathrm{BRL} \\
\text { million) }\end{array}$ & 2,126 & 634.50 & 410.39 & 0.89 & $3,511.41$ & $2,126.00$ \\
\hline Age (years) & 2,388 & 6.44 & 5.62 & 0.01 & 26.34 & 4.88 \\
\hline
\end{tabular}

Note: The sampling period was from January of 2010 to December of 2018. All variables presented in the table are in decimal format and were calculated on a quarterly basis for every month of the period. "Alpha" is the Jensen's (1968) alpha expressed on a quarterly basis, calculated using a function of the Economatica ${ }^{\circledR}$ database that considers as parameters the monthly data with a 36-month history of the "Treasury Financial Bill" (Letra Financeira do Tesouro - LFT) with maturity in 252 days and the return of the IBrX index; "flow" is the percentage variation in fund flow as according to equation 1; " $R$ " is the quarterly return disclosed by the fund; "RGap" is the return gap as defined by equation 2; "RHold" is the return of the portfolio disclosed at the start of the quarter in the buy-and-hold form; "RIbov" is the quarterly return of the Bovespa Index (Ibovespa); "RIBrX" is the quarterly return of the IBrX 100 stock index; "ManFee" is the quarterly equivalent at simple interest of the annual management fee disclosed; "LFT" is the quarterly rate of the 252-day LFT; "AUM" is the fund's assets under management; "age" is the fund's age in years; "obs." is the number of funds-month in the data panel; and "SD" is the standard deviation of the variable.

Source: Elaborated by the authors based on the fund sample obtained from the Economatica ${ }^{\circledR}$ database. 
Table 3 presents regression models 1 to 6 , where the percentage variation in fund flows $\left(\right.$ Flow $\left._{i, t}\right)$ is the dependent variable, as indicated by equation 3 , using the quarters beginning in January, March, June, and September. Model 7 employs the quarters starting in February, May, August, and November and model 8 refers to the quarters starting in March, June, September, and December. It warrants mentioning that the models presented in Table 3 are chosen based on all the models executed, using each one of the variables in isolation, as well as some simultaneously, and for all the quarterly samples starting in January, February, or March, respectively.

The results are partially similar to the U.S. results of Dyakov and Verbeek (2019) and Sirri and Tufano (1998) and indicate that investors direct their capital according to the fund's returns and buy and hold of the portfolio of the previous quarter and the Jensen's alpha, but the significance of the return gap coefficient varied according to the start of the quarter (models 4,7 , and 8 ), being significant in model 8 , marginally significant in model 7 , and not significant in model 4 . It is noted that there was significance for the two components of the return gap in Table 3. Thus, the results are inconclusive regarding the influence of the return gap on fund flow.

The management fee did not present any variation in time and was not included in the estimate with panel methods; however, it presented a negative and significant sign in a pooled ordinary least squares analysis, shown in model 2 of Table 3, indicating that investors tend to follow funds that have lower management fees, or that, similarly, present higher returns, as higher management fees reduce the net return of the stock funds. The Ibovespa return achieved significance in its relationship with future fund flow, which confirms the evidence of Sanvicente (2002). The fund's AUM maintained a negative and significant relationship with the percentage variation in the fund's flow, confirming that bigger funds raise less in relative terms. The fund's age, in general, did not present significant coefficients.

The evidence revealed by the models of Table 3 suggests that the fund's past returns influence the allocation, contrasting with the evidence of Sanvicente (2002), but they do not present consistent results regarding the relationship between the return gap and the variation in fund flow. This result is consistent with the non-rejection of $\mathrm{H}_{1}$, which did not predict a positive relationship between the return gap and the variation in fund flow, as the significance of the relationship did not occur in all formulations of the models. These inconclusive results are only partially consistent with those of Dyakov and Verbeek (2019) and Kacperczyk et al. (2008). From a practical viewpoint, the results do not imply that investors calculate the return gap and employ it to decide where to direct their resources. They merely suggest that investors demonstrate a preference for stock funds with a higher past return and, at best, use additional information that is unobservable through historical or public data for decision making about where to allocate their capital.

Table 3

Stock fund flow and return gap

\begin{tabular}{|c|c|c|c|c|c|c|c|c|}
\hline Variables & (1) & (2) & (3) & (4) & (5) & (6) & (7) & (8) \\
\hline \multirow{2}{*}{ RHold $_{t-1}$} & $0.35^{* * *}$ & $0.38^{* * *}$ & & & & & & \\
\hline & $(4.07)$ & $(4.35)$ & & & & & & \\
\hline \multirow{2}{*}{ ManFee $_{t-1}$} & & $-13.77^{* * *}$ & & & & & & \\
\hline & & $(-2.64)$ & & & & & & \\
\hline \multirow{2}{*}{$\operatorname{RGap}_{t-1}$} & & & 0.48 & 0.13 & 0.02 & 0.56 & 0.48 & $0.89^{* * *}$ \\
\hline & & & $(1.04)$ & $(0.29)$ & $(0.07)$ & (1.36) & $(1.04)$ & (3.01) \\
\hline \multirow{2}{*}{$R_{t-1}$} & & & & $0.36^{* * *}$ & & & & \\
\hline & & & & $(3.89)$ & & & & \\
\hline \multirow{2}{*}{ Alpha $a_{t-1}$} & & & & & $3.03^{* * *}$ & & & \\
\hline & & & & & $(3.47)$ & & & \\
\hline \multirow{2}{*}{ RIbov $_{t-1}$} & & & & & & $0.14^{* *}$ & & \\
\hline & & & & & & (2.04) & & \\
\hline \multirow{2}{*}{ Age } & 0.00 & -0.01 & 0.00 & 0.00 & $0.10^{*}$ & 0.00 & 0.00 & 0.01 \\
\hline & $(-0.02)$ & $(-0.67)$ & $(0.37)$ & $(-0.04)$ & $(2.00)$ & $(0.98)$ & $(0.37)$ & $(0.39)$ \\
\hline \multirow{2}{*}{ AUM } & $-0.06^{* * *}$ & $-0.04^{* * *}$ & $-0.06^{* * *}$ & $-0.06^{* * *}$ & $-0.06^{* *}$ & $-0.06^{* * *}$ & $-0.06^{* * *}$ & $-0.04^{* *}$ \\
\hline & $(-3.99)$ & $(-2.92)$ & $(-4.18)$ & $(-3.95)$ & $(-2.18)$ & $(-4.06)$ & $(-4.18)$ & $(-2.52)$ \\
\hline
\end{tabular}


Table 3

Cont.

\begin{tabular}{lccccccccc}
\hline Variables & $\mathbf{( 1 )}$ & $\mathbf{( 2 )}$ & $\mathbf{( 3 )}$ & $\mathbf{( 4 )}$ & $\mathbf{( 5 )}$ & $\mathbf{( 6 )}$ & $\mathbf{( 7 )}$ & $\mathbf{( 8 )}$ \\
\hline \multirow{2}{*}{ Constant } & $0.40^{* * *}$ & $0.34^{* * *}$ & $0.37^{* * *}$ & $0.39^{* * *}$ & -0.45 & $0.40^{* * *}$ & $0.37^{* * *}$ & $0.24^{* *}$ \\
\cline { 2 - 9 } & $(3.67)$ & $(3.86)$ & $(3.55)$ & $(3.65)$ & $(-1.27)$ & $(3.78)$ & $(3.55)$ & $(2.22)$ \\
\hline Obs. & 658 & 658 & 658 & 659 & 506 & 658 & 658 & 645 \\
\hline $\mathrm{R}^{2}$ & 0.07 & 0.09 & 0.06 & 0.12 & 0.07 & 0.06 & 0.06 & 0.04 \\
\hline
\end{tabular}

Note: The sampling period was from January of 2010 to December of 2018. Regressions in the form of equation 3 using the panel method with fixed effects due to the significant value of the Hausman test, except for model 2, estimated using pooled ordinary least squares because "ManFee," which is the quarterly equivalent at simple interest of the annual management fee disclosed, does not represent any variation in time for all the funds and for model 8, in which the Hausman test indicated random effects. All variables were calculated on a quarterly basis and refer to the quarters beginning in January, April, July, and October, except for model 7, which refers to the quarters starting in February, May, August, and November, and model 8, which refers to the quarters starting in March, June, September, and December. The simultaneous inclusion of highly and significantly correlated explanatory variables was avoided. The dependent variable is Flow ${ }_{i, t}$, which is the percentage variation in flow as according to equation 1. "RHold" is the return of the portfolio disclosed at the start of the quarter in the buy-and-hold form; "RGap" is the return gap defined by equation 2; " $R$ " is the quarterly return disclosed by the fund; "Alpha" is the Jensen's (1968) alpha expressed on a quarterly basis, calculated using a function of the Economatica ${ }^{\circledR}$ database that considers as parameters the monthly data with a 36-month history of the "Treasury Financial Bill" (Letra Financeira do Tesouro - LFT) with maturity in 252 days and the return of the IBrX index; "RIbov" is the quarterly return of the Bovespa Index (Ibovespa); "age" is the fund's age in years; "AUM" is the logarithm of the fund's assets under management at the end of each quarter in millions; "obs." is the number of funds-month in the data panel. Student's t-test in parentheses.

$*, * *, * * *=10,5$, and $1 \%$ statistical significance, respectively.

Source: Elaborated by the authors using Stata based on the funds sample obtained from the Economatica ${ }^{\circledR}$ database.

\subsection{Return Gap and Future Returns}

This section presents the results of tests that verify whether the investors in Brazilian stock funds with historically higher return gaps will obtain a higher return on their investments. Table 4 presents the descriptive statistics for the return gap in the annual form in each one of these samples. It is interesting to observe that the standard deviation is higher in the samples with the highest return gaps $\left(5^{\text {th }}\right.$ quintile and $2^{\text {nd }}$ half $)$, as well as the range between the minimum and maximum. This suggests that the distribution of the annual return gap is not similar when comparing each one of the subsamples used in Table 4 and that some observations (funds-month) may be outliers and influence the behavior of the subsample. It is possible that the highest return gap segments of the sample presented a higher standard deviation due to the survivorship bias derived, perhaps, from the heavy weight of successful funds, resulting from the way the sample is obtained.

Table 5 portrays the results for the regression models in the form of equation 4 . Only the quarters starting in January, April, July, and October were considered in the analysis portrayed here, although quarters starting in the other months were also considered in additional tests that are not shown. It warrants mentioning that models using the funds' past returns, in the buy-and-hold or observed form, were not employed, as the focus of this article is on the potential of the return gap to identify funds with good future performance. Other Brazilian authors have already made that type of analysis to verify the persistence of returns in Brazil (Andaku \& Pinto, 2003; Nerasti \& Lucinda, 2016). Moreover, the $W M L$ factor already reflects the impact of past returns on the model.

Table 4

Descriptive statistics of the annual return gap according to subsamples

\begin{tabular}{|c|c|c|c|c|c|c|}
\hline Sample & Obs. & Mean & Median & Minimum & Maximum & SD \\
\hline $1^{\text {st }}$ quintile & 314 & -0.040 & -0.027 & -0.281 & -0.009 & 0.038 \\
\hline $2^{\text {nd }}$ quintile & 314 & 0.003 & 0.003 & -0.008 & 0.012 & 0.006 \\
\hline $3^{\text {rd }}$ quintile & 314 & 0.021 & 0.021 & 0.012 & 0.031 & 0.005 \\
\hline $4^{\text {th }}$ quintile & 314 & 0.043 & 0.042 & 0.031 & 0.057 & 0.008 \\
\hline $5^{\text {th }}$ quintile & 314 & 0.111 & 0.083 & 0.057 & 0.907 & 0.099 \\
\hline
\end{tabular}




\section{Table 4}

Cont.

\begin{tabular}{|c|c|c|c|c|c|c|}
\hline Sample & Obs. & Mean & Median & Minimum & Maximum & SD \\
\hline $1^{\text {st }}$ half & 785 & -0.011 & -0.002 & -0.281 & 0.021 & 0.034 \\
\hline $2^{\text {nd }}$ half & 785 & 0.066 & 0.049 & 0.021 & 0.907 & 0.073 \\
\hline Full & 1,570 & 0.028 & 0.021 & -0.281 & 0.907 & 0.069 \\
\hline
\end{tabular}

Note: The sampling period was from January of 2010 to December of 2018. All variables are in decimal format and were calculated on an annual basis for every month of the sample. The "1st quintile" sample is composed of the worst $20 \%$ of observations in terms of annual return gap and the "5th quintile" sample is composed of the best 20\%; the "1st half" sample contains the worst $50 \%$ of observations in terms of annual return gap and the "2nd half" sample contains the best $50 \%$; "obs." is the number of funds-month in the data panel; and "SD" is the standard deviation of the variable.

Source: Elaborated by the authors based on the sample of funds obtained from the Economatica ${ }^{\circledR}$ database.

The return of the stock funds classified among the $20 \%$ best performances in terms of annual return gap $\left(5^{\text {th }}\right.$ quintile) has a positive and significant coefficient with the annual return gap. Investors that allocate their capital in the funds with the higher historical annual return gap, which are all positive, as Table 4 shows, tend to obtain positive future returns, which suggests persistence of the positive returns for the most successful stock funds. However, the alpha of these funds in Table 5 is null, on average.

The results for the two samples obtained according to the median are analogous. An analysis with the Jensen's alpha as the dependent variable instead of the annual return, without Carhart's (1997) risk factors, achieved similar results and was not included in this article, but is available from the authors. These results reject the null hypothesis $\mathrm{H}_{2}$, which predicted there was no relationship between the stock funds' future returns and the return gap, and they find a positive and significant relationship, which is consistent with the results of Dyakov and Verbeek (2019) and Kacperczyk et al. (2008).

There is no significance for the return gap in the other quintiles, which reinforces this conclusion. However, it is interesting to note that the alpha in Table 5 is positive and significant, on average, for the first three quintiles. The investors that allocate their capital the in funds with a historically lower annual return gap tend to obtain positive future returns in excess of the risk factors used, which suggested undervaluation of the stock funds in this segment of the sample, as indicated by Kwak (2018). A second investment strategy therefore emerges, complementary to investing in stock funds with a higher return gap, which would be to look at the stock funds with the lowest return gap in order to invest in funds neglected by investors and whose managers appear to present greater alpha generation potential.

It also warrants mentioning the results for Carhart's (1997) risk factors. The beta is positive and significant. The $S M B$ and $H M L$ coefficients are negative and significant for all the segments of the sample and suggest that the stock funds had their portfolios dominated by bigger and growth companies.

An inspection was made of the 10 biggest positions of the funds' portfolios at the end of every year and the frequent presence of large companies in the market was verified, which does not characterize these stock funds, in general, as small stocks funds. Regarding the growth aspect, in turn, it would be necessary to collect appropriate metrics to assess the biggest positions of each fund, and this analysis transcends the aim of this article. The coefficient of the $W M L$ factor was positive in the models in which it presented significance, suggesting some preference of the managers for winning companies in the previous year.

Next the sample was divided into two subperiods: the first, from January of 2010 to June of 2014, which presented a cumulative variation of $-22.5 \%$ of the Ibovespa; the second, from July of 2014 to December of 2018, with a cumulative variation of $65.3 \%$ of the Ibovespa. The analysis of these subperiods suggests that the results reported here derive particularly from the second period. This analysis was not included in this article due to the limited number of pages.

These results reveal the importance of the return gap for choosing stock funds that will be successful in the near future. It is clear that the return gap calculation may be outside the reach of most investors, but the managers of the stock funds or databases such as Economatica ${ }^{\circledR}$, Bloomberg ${ }^{\circledR}$, or Quantum ${ }^{\circledR}$ could calculate and disclose this measure, which would be one more to guide investors' decisions. Moreover, regulators could include it as a possible measure to appear in the factsheets of funds.

Finally, it warrants mentioning that funds that did not survive would tend to present worse returns, as Mendonça et al. (2017) showed, possibly with a negative variation in allocation flows. Although it is difficult to say what the predominant sign of their return gaps should be, they may also be negative. The inclusion of these funds in the sample could alter the results for the stock funds with 
the $20 \%$ worst performances in terms of annual return gap ( $1^{\text {st }}$ quintile) and invalidate the evidence previously presented for that quintile, but there should be no change in the main results obtained for the stock funds in the quintile with the highest return gap.

The selection of a random sample of surviving funds, which would probably be dominated by smaller funds than those chosen for the sample used here, could alter the results presented, which may have been influenced by the fact that the stock funds examined here are among the biggest in the market. Thus, as always occurs, these results may be preliminary as they are applicable to the sample and to the period chosen and may be revised by examining different samples.

Table 5

Future annual return of the stock funds and annual return gap

\begin{tabular}{|c|c|c|c|c|c|c|c|c|}
\hline Sample & Full & $1^{\text {st }}$ quintile & $2^{\text {nd }}$ quintile & $3^{\text {rd }}$ quintile & $4^{\text {th }}$ quintile & $5^{\text {th }}$ quintile & $1^{\text {st }}$ half & $2^{\text {nd }}$ half \\
\hline \multirow{2}{*}{ RGap } & 0.16 & 0.32 & 1.25 & -2.02 & 1.23 & $1.41^{* * *}$ & -0.16 & $1.25^{* * *}$ \\
\hline & $(1.26)$ & $(0.45)$ & $(0.44)$ & $(-0.65)$ & $(0.48)$ & $(6.40)$ & $(-0.39)$ & $(7.95)$ \\
\hline \multirow{2}{*}{ MRP } & $0.34^{* * *}$ & $0.57^{* * *}$ & $0.27^{* * *}$ & $0.24^{* * *}$ & $0.24^{* * *}$ & $0.28^{* * *}$ & $0.38^{* * *}$ & $0.26^{* * *}$ \\
\hline & $(9.13)$ & (4.30) & (3.56) & $(3.47)$ & (3.66) & (3.56) & $(6.50)$ & $(6.33)$ \\
\hline \multirow{2}{*}{ SMB } & $-0.14^{* * *}$ & $-0.19^{*}$ & $-0.17^{* *}$ & $-0.15^{* * *}$ & $-0.11^{* * *}$ & $-0.12^{* * *}$ & $-0.15^{* * *}$ & $-0.14^{* * *}$ \\
\hline & $(-5.40)$ & $(-1.99)$ & $(-3.27)$ & $(-3.16)$ & $(-2.42)$ & $(-2.03)$ & $(-3.75)$ & $(-4.92)$ \\
\hline \multirow{2}{*}{$\mathrm{HML}$} & $-0.27^{* * *}$ & $-0.45^{* * *}$ & $-0.23^{* * *}$ & $-0.24^{* * *}$ & $-0.16^{* * *}$ & $-0.20^{* * * *}$ & $-0.27^{* * *}$ & $-0.21^{* * *}$ \\
\hline & $(-7.44)$ & $(-3.39)$ & $(-3.15)$ & $(-4.14)$ & $(-2.26)$ & $(-2.67)$ & $(-5.33)$ & $(-4.96)$ \\
\hline \multirow{2}{*}{ WML } & 0.04 & 0.02 & 0.01 & -0.01 & 0.04 & $0.15^{* *}$ & 0.02 & $0.06^{* *}$ \\
\hline & $(1.56)$ & $(0.22)$ & $(0.21)$ & $(-0.19)$ & $(0.86)$ & (2.59) & $(0.40)$ & $(2.07)$ \\
\hline \multirow{2}{*}{ Alpha } & $0.08^{* * *}$ & $0.13^{* * *}$ & $0.04^{* * *}$ & $0.13^{* *}$ & 0.02 & -0.03 & $0.08^{* * *}$ & 0.02 \\
\hline & $(8.57)$ & $(2.80)$ & (2.88) & (2.14) & $(0.20)$ & $(-1.05)$ & (5.30) & (1.15) \\
\hline Obs. & 452 & 96 & 91 & 87 & 87 & 91 & 233 & 219 \\
\hline$R^{2}$ & 0.24 & 0.23 & 0.34 & 0.34 & 0.24 & 0.54 & 0.22 & 0.46 \\
\hline
\end{tabular}

Note: The sampling period was from January of 2010 to December of 2018. Regressions using the panel method with fixed effects, as indicated by the Hausman test. The dependent variable is the 12-month cumulative future return at the end of quarter $t=5$ subtracted from the equivalent 12-month risk-free rate. The explanatory variable of interest "RGap" is the annual return gap calculated for the compound interest cumulative of the four previous quarterly return gaps at the end of quarter t=0. Each model refers to a sample obtained according to the quintiles or median of the annual return gap. "MRP" is the market risk premium, "SMB" is the small stocks risk premium, "HML" is the value stocks risk premium, and "WML" is the winning stocks risk premium. These risk factors, as well as the risk-free rate, were obtained from the Center for Finance Studies of the University of São Paulo (Nefin, 2015). All variables presented in the table were calculated on an annual basis and refer to the quarters starting in January, April, July, and October. Student's t-test in parentheses. "Alpha" is the intercept of the models and indicates return in excess of the risk factors; "obs" is the number of funds-quarters of each model.

$*, * *, * *=10,5$, and $1 \%$ statistical significance, respectively.

Source: Elaborated by the authors using Stata based on the funds sample obtained from the Economatica ${ }^{\circledR}$ database and risk factors obtained from Nefin.

\section{CONCLUSIONS}

This article investigated whether investors that operate in the Brazilian market identify stock funds whose future performance will be attractive using a set of possibly qualitative and subjective information about the fund's manager, which is not directly observable through the funds' historical data or public characteristics.

This information was represented by the return gap of Kacperczyk et al. (2008), which measures the value added by the stock fund's managers in relation to the buy and hold return of the fund's portfolio lagged by three months.
Dyakov and Verbeek (2019) and Kacperczyk et al. (2008) showed that the future performance of stock funds in the United States can be predicted by their return gaps.

A parsimonious sample was used of 22 stock funds from the 22 biggest independent stock fund managers in the period from January of 2010 to December of 2018, as the buy-and-hold return of every asset in the portfolio of every fund had to be estimated monthly and manually, since no simple way of automating the process was available. 
The results indicate that the return gap of the stock funds did not maintain a consistent positive and significant relationship with the variation in the capital allocation flow on the part of the investors and the U.S. results are not sustained for Brazil, leading to the conclusion that there is no relationship between unobservable information, represented by the return gap, and fund flows.

The results also suggest that investors in Brazilian stock funds could distinguish funds that will probably have good performance from the rest by using unobservable information about the management, represented by the return gap. Future performance was measured in terms of both the fund's return and its Jensen's alpha. The greater a fund's return gap, the higher its return in the following 12 months, even after adjusting for Carhart's (1997) risk factors, which suggests some persistence in the returns of the stock funds over terms shorter than a year.

On the other hand, it is important to note that the stock funds with the lowest return gaps presented a positive alpha on average, suggesting that some of these funds, those that capture less money, were relegated by investors. These results were largely consistent for quarters beginning in all the months of the years, consistent with the U.S. results, and stronger in the most recent half of the sampling period, when the market was on the rise.

This article contributes to the Brazilian literature on the topic as the results suggest that information of a qualitative or subjective nature about the unobservable acts and attributes of managers may contribute to better stock fund selection, besides the characteristics of these funds already identified by other authors. The study also indicates that the return gap is an important measure for stock fund selection, although it can be complex to calculate for most individual investors. However, it would be very simple for stock fund managers to present the return gap in their disclosure material and for database software to include it among its metrics.

The results presented here are subject to limitations, including inconsistencies in the data disclosed by the CVM that prevented the inclusion of some funds, few stock funds of the biggest independent managers with a long history of data (more than nine years), and the amount of manual work involved in calculating the return gap, which requires the returns of every asset in the funds' portfolios to be calculated, imposing parsimony over the sample size.

An interesting extension of this article would be to verify, in detail, situations of over or undervaluation of stock funds according to the return gap (Kwak, 2018). Another possible extension would be to verify if there was an impact of the survivorship bias derived from the sample selection process that favored the oldest stock funds of the biggest independent managers, although obtaining the data on funds that did not survive is not very easy.

Future studies could choose a random sample of surviving stock funds, as well as considering samples of independent stock funds and of managers affiliated with large financial conglomerates operating in the country. Finally, it is worth observing that an alternative method to analyzing regressions for every return gap quintile presented here could employ logistic regressions, classifying the best performing funds according to their alpha or some type of premium in relation to a benchmark.

\section{REFERENCES}

Andaku, F. T. A., \& Pinto, A. C. F. (2003). A persistência de desempenho dos fundos de investimento em ações no Brasil. Revista de Economia e Administração, 2(2), 23-33.

Associação Brasileira das Entidades dos Mercados Financeiro e de Capitais. (2018). Ranking de gestores de fundos de investimento.

Carhart, M. (1997). On persistence in mutual fund performance. The Journal of Finance, 52(1), 57-82.

Ceretta, P. S., \& Costa, N. C. A., Jr. (2001). Avaliação e seleção de fundos de investimento: Um enfoque sobre múltiplos atributos. Revista de Administração Contemporânea, 5(1), 7-22.

Comissão de Valores Mobiliários (2014). CVM Instruction 555, of December 17 of 2014. Describes the constitution, administration, functioning, and disclosure of information of investment funds. http://www.cvm.gov.br/legislacao/ instrucoes/inst 555. html
Daltro, A. B. V., \& Leal, R. P. C. (2019). Fixed income and passive asset allocation outperformance in Brazil. Journal of Wealth Management, 22(2), 37-49.

Dyakov, T., \& Verbeek, M. (2019). Can mutual fund investors distinguish good from bad managers? International Review of Finance, 19(3), 505-540.

Fama, E. F., \& French, K. R. (1993). Common risk factors in the returns on stocks and bonds. Journal of Financial Economics, 33(1), 3-56.

Gruber, M. J. (1996). Another puzzle: The growth in actively managed mutual funds. The Journal of Finance, 51(3), 783-810.

Investment Company Institute. (2019). Quarterly worldwide mutual fund market. https://www.ici.org/info/ww_q1_19_ public_report_us.xls

Ippolito, R. A. (1992). Consumer reaction to measures of poor quality: Evidence from the mutual fund industry. The Journal of Law and Economics, 35(1), 45-70. 
Januzzi, F. V., Botrel P. C. M. G. G., \& Bressan, A. A. (2017). As captações líquidas afetam o desempenho dos fundos de ações Ibovespa-ativo? Um estudo aplicado ao mercado brasileiro. Revista de Finanças Aplicadas, 8(1), 1-24.

Jensen, M. (1968). The performance of mutual funds in the period 1945-1964. The Journal of Finance, 23(2), 389-416.

Kacperczyk, M., Sialm, C., \& Zheng, L. (2008). Unobserved actions of mutual funds. The Review of Financial Studies, 21(6), 2379-2416.

Kwak, S. K. (2018). Institutional theory of naive money (Doctoral Thesis). Massachusetts Institute of Technology. https://dspace.mit.edu/bitstream/ handle/1721.1/120202/1082523221-MIT.pdf? sequence=1

Matos, P. R. F., Penna, C. M., \& Silva, A. B. G. (2015). Fundos mútuos de investimento em ações no Brasil: Incentivos, gestão e convergência. Brazilian Business Review, 12(2), 115-147.

Mendonça, J. A., Campani, C. H., \& Leal, R. P. C. (2017). A escolha de fundos de ações e o investidor individual. Revista de Administração Contemporânea, 21(special number), 4162 .
Milani, B., \& Ceretta, P. S. (2012). Tamanho e rentabilidade dos fundos brasileiros de investimento em ações. Revista Alcance, 19(4), 461-475.

Nerasti, J. N., \& Lucinda, C. R. (2016). Persistência de desempenho em fundos de ações no Brasil. Revista Brasileira de Finanças, 14(2), 269-297.

Núcleo de Estudos em Finanças da Universidade de São Paulo. (2015). Methodology. Nefin. http://www.nefin.com.br/ Metodologia/Methodology.pdf

Oliveira, B. G., Filho, \& Sousa, A. F. (2015). Fundos de investimento em ações no Brasil: métricas para avaliação de desempenho. REGE-Revista de Gestão, 22(1), 61-76.

Sanvicente, A. Z. (2002). Captação de recursos por fundos de investimento e mercado de ações. Revista de Administração de Empresas, 42(3), 1-9.

Silva, S. E., Roma, C. M., \& Iquiapaza, R. A. (2018). A taxa de administração sinaliza o desempenho dos fundos de investimento em ações no Brasil? Revista de Educação e Pesquisa em Contabilidade, 12(3), 286-312.

Sirri, E. R., \& Tufano, P. (1998). Costly search and mutual fund flows. The Journal of Finance, 53(5), 1589-1622. 